\title{
Thomas-Simon Gueullette, Contes
}

\section{Paola Perazzolo}

\section{OpenEdition}

Journals

\section{Edizione digitale}

URL: http://journals.openedition.org/studifrancesi/5955

DOI: 10.4000/studifrancesi.5955

ISSN: 2427-5856

\section{Editore}

Rosenberg \& Sellier

\section{Edizione cartacea}

Data di pubblicazione: 1 mai 2011

Paginazione: 171-172

ISSN: 0039-2944

\section{Notizia bibliografica digitale}

Paola Perazzolo, «Thomas-Simon Gueullette, Contes», Studi Francesi [Online], 163 (LV | I) | 2011, online dal 30 novembre 2015, consultato il 08 janvier 2021. URL: http://journals.openedition.org/ studifrancesi/5955 ; DOI: https://doi.org/10.4000/studifrancesi.5955

Questo documento è stato generato automaticamente il 8 janvier 2021.

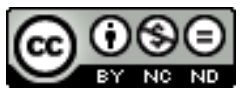

Studi Francesi è distribuita con Licenza Creative Commons Attribuzione - Non commerciale - Non opere derivate 4.0 Internazionale. 


\title{
Thomas-Simon Gueullette, Contes
}

\author{
Paola Perazzolo
}

\section{NOTIZIA}

thomas Simon Gueullette, Contes. Edition critique établie sous la direction de JeanFrançois PERRIN, Paris, Champion, 2010 («Bibliothèque des Génies et des Fées», 9), 3 tomi, pp. 2389.

Questi tre grossi tomi, che costituiscono il nono volume della collana «Bibliothèque des Génies et des Fées» edita da Champion, offrono un'edizione critica dei contes orientaleggianti che Guellette ha composto e pubblicato tra il 1712 e il 1732 (nel primo tomo Les Soirées Bretonnes edite da Christelle Bahier-Porte, Les Mille et Un Quarts d'Heures e i Contes Tartares curati da Carmen Ramírez; nel secondo Les Aventures merveilleuses du mandarin Fum-Hoam. Contes Chinois, e Les Sultanes de Guzarate, ou les Songes des hommes éveillés. Contes Mogols, edizioni critiche di Jean-François Perrin; nel terzo Les Mille et Une Heures, Contes Péruviens, a cura di Marie-Françoise Bosquet). Magistrato appassionato di letteratura (è nota la sua collaborazione come autore e traduttore con la troupe della Comédie Italienne di Luigi Riccoboni) e lettore onnivoro, nella sua produzione narrativa l'autore rielabora a livello di trame, personaggi, situazioni, riflessioni e descrizioni un repertorio quantomai eterogeneo, che spazia dalla letteratura medievale alla tradizione della novella italiana trecentesca, dal repertorio favolistico francese alla tradizione orientale veicolata da Galland o Pétis de La Croix, dalla letteratura narrativa e morale del xvir secolo ai racconti di viaggio e alla produzione teatrale: come sottolinea Jean-François Perrin nella sua ottima «Introduction générale», i contes di Gueullette possono essere considerati come potenziali «micro-bibliothèques des romans, où l'on peut trouver l'imitation orientalisée de tout ce qui a cours en la matière sur l'étal des libraires du XvIII ${ }^{\text {e }}$ siècle» (p. 27). Se la poetica di Gueullette «n'est donc pas d'invention, mais de montage et de composition» (p.36), i materiali a disposizione vengono però filtrati dall'esprit settecentesco: l'intento didattico o morale e l'attenzione alla realtà politica e sociale permettono infatti di leggere come «fictions critiques au sens des Lumières» (p.34) opere cui si può inoltre riconoscere una certa originalità 
formale - è il caso dei récit-cadres delle Mille et Un Quarts d'Heure e dei Contes Tartares, dove il dialogismo tra narratore e sultano assume la forma di discussioni letterarie a livello formale e tematico, o della formula di narratori multipli dei Contes Péruviens - e una struttura inedita a livello di composizione generale, di subordinazione dei racconti, di scelta dei punti di vista narrativi.

2 Questi contes, tradotti in diverse lingue durante il XVIII secolo e ripubblicati nel Cabinet des fées nel secolo successivo, hanno goduto all'epoca di una notevole fortuna, ma il successivo scemare dell'interesse critico li ha resi di difficile accesso per un lettore contemporaneo. L'averli messi a disposizione del pubblico costituisce quindi uno dei meriti di un'operazione editoriale che si distingue per cura, precisione e chiarezza al fine di ritracciare «un moment signalé de l'histoire de la transmission de la matière d'Orient et de la tradition narrative européenne ancienne jusqu'à Straparole» (quarta di copertina). Gli editori restituiscono testi modernizzati per quanto riguarda ortografia e sintassi e corredati da un'introduzione, un ricco apparato di note lessicali, linguistiche ed esplicative, utili «Notices» e la storia editoriale di ogni raccolta, contribuendo così all'apprezzamento e alla miglior comprensione non solo di un autore oggi poco noto, ma anche della poetica e della storia di una forma narrativa - il conte meraviglioso dell'epoca classica - dalla straordinaria ricchezza intertestuale. 